\title{
SEMINARIO NACIONAL DE PENSAMIENTO SOBRE LA UNIVERSIDAD
}

Arq. Mgst. Diego Jaramillo Paredes

Presidente del Simposio Permanente sobre la Universidad

Diversas son las razones que han dificultado que la Universidad despliegue esta mirada sobre sí misma, realice su autocrítica y su prospectiva: unas tienen relación con la crisis de la razón, de aquella razón que sustentó a la Universidad desde su constitución moderna; otras con los radicales cambios que se producen en la sociedad posindustrial y que han dibujado un paisaje incierto y confuso; y otras con los procesos de imposición desde el Estado de una nueva estructura académica, legal y administrativa para el sistema de educación superior y la urgencia de la universidades de ajustarse a estos requerimientos.

Pensar hoy la Universidad nos enfrenta al reto de superar el debate iniciado en la segunda mitad del siglo pasado, debate que sitúa la razón de ser de la Universidad en relación con las posiciones modernizadoras o reformistas del estado; y situar la reflexión sobre la Universidad en el contexto de la globalización, de la sociedad de la información y de las tecno-ciencias, momento de predominio de la razón instrumental al servicio de los intereses del capitalismo global. Pensar la Universidad supone pensar en primera instancia la necesidad por el valor actual de la comprensión del mundo y el lugar del ser humano en él.

Los fundamentos de la Universidad actual quizás haya que construirlos en el marco del debate y el ejercicio de una nueva razón que supere las disciplinas, que esclarezca el abordaje universitario de la diversidad de saberes; en definitiva, en el marco de un inédito modo de pensar que devenga en unas nuevas humanidades. 
Para avivar este debate, permanente e inacabable, la Universidad del Azuay, retomando la iniciativa de Alfonso Borrero, ha creado el Simposio Permanente de Pensamiento sobre la Universidad como un espacio abierto en el cual la Universidad se piensa a sí misma y en el que se propicia el debate del pensamiento sobre ella, desde una perspectiva teórica y con especial énfasis en América Latina.

En el contexto de este Simposio Permanente, la Universidad del Azuay convocó a las universidades ecuatorianas al I SEMINARIO NACIONAL DE PENSAMIENTO SOBRE LA UNIVERSIDAD, IOS días 16 y 17 de noviembre de 2017. Esta publicación recoge las ponencias de distinguidos académicos e intelectuales invitados a este Seminario y los artículos de Hernán Malo G. S. J., Ex Rector de la Pontificia Universidad Católica del Ecuador, quien estuvo estrechamente ligado a la creación de nuestra Universidad, y cuyas reflexiones contribuyeron y contribuyen de manera sustancial al debate que nos anima; y, de Alfonso Borrero C. S.J., Ex Rector de la Pontificia Universidad Javeriana de Colombia e iniciador del Simposio Permanente sobre la Universidad en ese país.

Hemos incluido también, el Modelo Educativo de la Universidad del Azuay, que expresa el ejercicio libre y autónomo de esta Universidad para pensarse a sí misma y definirse. El Modelo Educativo entendido como la mediación necesaria entre la razón de ser de la Universidad y el proyecto de Universidad que aspiramos. 